\title{
From individual to collective immunity: The role of the venom as antimicrobial agent in the Stenogastrinae wasp societies
}

\author{
David Baracchi ${ }^{\mathrm{a}, \mathrm{b}, *}$, Giuseppe Mazza ${ }^{\mathrm{a}}$, Stefano Turillazzi ${ }^{\mathrm{a}, \mathrm{b}}$ \\ a Università degli Studi di Firenze, Dipartimento di Biologia Evoluzionistica "Leo Pardi", Via Romana 17, 50125 Firenze, Italy \\ ${ }^{\mathrm{b}}$ Centro Interdipartimentale di Spettrometria di Massa dell'Università di Firenze, Viale G. Pieraccini, 5000 Firenze, Italy
}

\section{A R T I C L E I N F O}

\section{Article history:}

Received 24 September 2011

Received in revised form 4 November 2011

Accepted 8 November 2011

Available online $\mathrm{xxxx}$

\section{Keywords:}

Social immunity

Herd immunity

Vespidae

Hover wasps

Antimicrobial peptides

MALDI-TOF

\begin{abstract}
A B S T R A C T
Sociality is associated with an increased risk of disease transmission and one of the first defense of the insect colonies is represented by antimicrobial secretions. In many eusocial hymenopteran species venom glands represent one of the most important source of antimicrobial substances. It is known that in highly eusocial species the venom is spread on both the cuticle of insects and the comb, thus becoming a component of the so called "social immunity". So far, it is never been ascertained whether this phenomenon is also present in more primitively eusocial and incipiently eusocial groups. Using incipiently eusocial hover wasps as model, we demonstrate that venom is present on insect cuticles and that it strongly acts against microorganisms. By contrast, the nest, regardless of materials, does not represent a "medium" where the venom is deposited by wasps in order to act as a social antiseptic weapon. Our findings discussed in an evolutionary perspective indicate that a certain degree of sociality or a sufficient number of individuals in an insect society are thresholds to be reached for the rise of complex and efficient forms of collective and social immunity as mechanisms of resistance to diseases.
\end{abstract}

(ㄷ) 2011 Elsevier Ltd. All rights reserved.

\section{Introduction}

Colonies of social insects may consist of thousands of individuals living in close proximity and characterised by a reduced genetic variability. These features may be conducive to contagious disease epidemics (Schmid-Hempel, 1998; Zasloff, 2002; Lawniczak et al., 2007). Since sociality is associated with significant costs due to the increased risk of disease transmission (Brockmann, 1984; Hughes and Boomsma, 2004; but see van Baalen and Beekman (2006) and Hughes et al. (2008)) resistance to parasitic infections has been a major contribution to the evolutionary success of these insects (Otvos, 2000). Indeed, one of the first defense of the colony is represented by the use of antimicrobial secretions usually produced by the colony members or collected from plants (Sadd and Schmid-Hempel, 2006). Social insects were described as "gland factories" (Billen and Morgan, 1998) and many of their antiseptic products have been deeply investigated in the last decades. In ants, the metapleural gland produces secretions with antiseptic and antifungal activity (Hölldobler and Wilson, 1990) while termites secrete strong antimicrobial compounds from their faecal pellets or from soldier frontal glands (Chen et al., 1998; Rosengaus et al.,

* Corresponding author at: Università degli Studi di Firenze, Dipartimento di Biologia evoluzionistica "Leo Pardi", Via Romana 17, 50125 Firenze, Italy. Tel.: +39 055 2288218; fax: + 39055222565

E-mail address: david.baracchi@gmail.com (D. Baracchi).
2000). Venom glands of various ants, wasps and bees produce several compounds with antimicrobial activity (Park et al., 1995; Orivel et al., 2001; Storey et al., 1991; Turillazzi, 2006) representing one of the most important source of antimicrobial substances in social Hymenoptera (Kuhn-Nentwig, 2003). In some cases, the use of venom is beyond the classical stereotype of defence against predators and can be considered as a component of the social immunity (Cremer et al., 2007; Wilson-Rich et al., 2009; Baracchi and Turillazzi, 2010; Baracchi et al., 2011). For example, Obin and Vander Meer (1985) demonstrated that the fire ant Solenopsis invicta dispenses small quantities of venom on the brood surface, presumably as an antimicrobic. In several species of honey bee, venom peptides with strong antimicrobial activity can be found both on the cuticle of the females and on the comb (Baracchi and Turillazzi, 2010; Baracchi et al., 2011). While antimicrobial peptides spread on an insect cuticle represent a kind of "personal immunity", acting as primary barriers to infections (Zasloff, 2002; Lambardi et al., 2007), the use of the nest as an antiseptic medium represents an excellent example of "collective immunity" (sensu Cotter and Kilner, 2011). Despite that, as far as we know, this form of collective immunity seem to be relegate to highly eusocial taxa, and it is never been ascertained whether this phenomenon is also present in more primitively eusocial and incipiently eusocial groups. In particular, we retain that the subfamily Stenogastrinae (hover wasps) may represent a key taxon to investigate, because its species show the most primitive social organisation among all 
the social wasps (Turillazzi, 1991, 1996) and, compared with the Polistinae and Vespidae, their colonies are small and contain only few individuals (Turillazzi, 1996). Several polar substances have already been reported on the cuticle of some hover wasp species (Baracchi et al., 2010) but it remains to clarify whether these compounds originate from the venom (usually the main source of epicuticular polar substances) and possess antimicrobial competence, and whether these simple societies achieved also complex forms of collective immunity (i.e. the use of the nest as antiseptic medium) like the ones observed in Polistes paper wasps. In this work, we first ascertain whether or not venom is the source of the e polar epicuticular compounds found on various species of female hover wasps, by mean of a mass spectrometric technique named matrix assisted laser desorption ionisation-time-of-flight mass spectrometry (MALDI-TOF MS). Then, we tested the activity of these polar substances against Gram-positive and Gram-negative bacteria and yeasts by means of microbiological assays. Finally, a mass spectrometry survey of venom peptides on the nests was performed. All our findings are discussed in an evolutionary perspective.

\section{Materials and methods}

\subsection{Nests and venom collection and cuticular compounds extraction}

The venom and the cuticular compounds of the following Stenogastrinae species, belonging to three genera, were analysed for medium molecular weight polar compounds: Eustenogaster calyptodoma, Eustenogaster micans, Liostenogaster campanulae, Liostenogaster flavolineata, Liostenogaster topographica, Liostenogaster vechti, Parischnogaster alternata, Parischnogaster mellyi, Parischnogaster jacobsoni, Parischnogaster striatula. All samples were collected in Pahang State (Malaysia) during January-February 2010. Ten females of each species were collected and killed by freezing soon after capture. Each wasp was rinsed in $300 \mu \mathrm{l}$ of methanol for 3 min to extract the epicuticular polar compounds. During the procedure each wasp was held by the tip of its abdomen using a pair of forceps to prevent any possible venom contamination of the solvent. The venom reservoir of each wasp was then collected after dissection of the insect and subsequently rinsed in $50 \mu \mathrm{l}$ of methanol (because of the small size of the venom reservoir with respect to the considerable length of the sting we were unable to extract the venom directly from the tip of the sting through a glass capillary). However, a previous work (Baracchi and Turillazzi, 2010) showed that the two different methods of venom sampling (direct extraction of the crude venom vs venom reservoir extraction) produced only very slightly different MALDI spectra in the range of 1000-4000 Da. The nest material from three nests of each species (and from one species belonging to a fourth genus, Metischnogaster drewseni) were also collected and extracted in $300 \mu \mathrm{l}$ of methanol for MS analysis. Twelve venom glands from one species of each genus ( $L$. vechti, E. calyptodoma, P. striatula) were pooled in groups of six specimens each for microbiological assays. Six glands of the females $M$. drewseni were also pooled together and used for microbiological assays. Finally, three nests from the same species of each genus were pooled together for microbiological assays.

\subsection{Mass spectrometry analyses}

\subsubsection{MALDI-TOF spectra profiling}

Methanol extracts of the nests, of the venoms and of the overall cuticle from each individual wasps were analysed with a MALDITOF/TOF Ultraflex III (Bruker Daltonics, Bremen, Germany). Positive ion spectra were acquired in reflectron mode, setting the Ions Source 1 at $25 \mathrm{kV}$, the Ion Source 2 at $21.9 \mathrm{kV}$ and the delay time at 20 ns. The matrix for MALDI-TOF experiments was a solution of $\alpha$ - cyano-4-hydroxycinnamic acid ( $\alpha$-CHCA) $(10 \mathrm{mg} / \mathrm{ml})$ dissolved onto a $70 / 30$ acetonitrile/TFA $0.1 \%$. One microlitre of the sample was mixed with MALDI matrix $(1: 1, \mathrm{v} / \mathrm{v})$, and the mixture was spotted in a stainless steel target. Eight hundred shots were automatically accumulated for each spectrum. External calibration was performed with the Bruker Standard Peptide Calibration kit $(\mathrm{m} / \mathrm{z}$ 1000-3500) and the peptidic fraction of the samples was acquired in the range $m / z$ 950-4000.

\subsubsection{Statistical analyses}

Calibrated spectra were imported into the ClinProTools ${ }^{\mathrm{TM}}$ (CPT) software and processed with a procedure suggested by the software manual and similar to that of a previous study in on cuticular and venom peptides (Baracchi and Turillazzi, 2010). For the analysis of the venom polar compounds only the venom spectra were loaded in the CPT, while, for the comparison between venom and cuticular profiles the corresponding spectra were loaded together for each single species. CPT parameters used for peak calculation were standardised in order to obtain comparable results: peak width: 0.01; smoothing (width: 5 Da, cycles: 1 ); average peak list calculation (relative threshold base peak: 0.01, signal-to-noise threshold: 3, limit peak number: 25/false); area calculation (integration type: zero level). Using these parameters, the program calculates the areas of the peaks of the venom and the cuticular spectra. This data set was used for statistical analyses. We first determined the percentage of each peak area with respect to the total of all peaks. We then calculate the average profiles values of both venom and cuticle for each species. Finally, a cluster analysis, using the average linkage (UPGMA) method and Pearson correlation among mean peaks as a dissimilarity measure, was used to group the samples (venom and cuticular average spectra for each species) in a hierarchical tree. All statistical analyses were performed using the statistical program SPSS ${ }^{\circledR}$ 13.0.

\subsection{Microbiological assays}

The Gram-positive strain, Bacillus subtilis ATCC 6633, and the Gram-negative strain, Escherichia coli JM109, were used as bacterial indicators. Petri dish with Luria-Bertani (LB) solid medium was plated with $10^{6}$ E. coli cells from an overnight culture in LB medium. Petri dish with nutrient agar (NA, Oxoid) medium was overlaid with $7 \mathrm{ml}$ of NA inoculated with $10^{6}$ B. subtilis spores. Saccharomyces cerevisiae S288C was used as yeast indicator. Petri dish with malt extract agar (MEA, Oxoid) was plated with $10^{6}$ spores of the yeast. Each pool of six individuals was taken to dryness and then re-suspended in $15 \mu \mathrm{l}$ of water and spotted $(5 \mu \mathrm{l}$ each) onto the three plates (B. subtilis, E. coli and S. cerevisiae) as well as water as control $(5 \mu \mathrm{l})$. The microbiological assays were repeated two times for all the genera except for $M$. drewseni. All the plates were incubated for $24 \mathrm{~h}$ at $30^{\circ} \mathrm{C}$. Penicillin G was used as standard for $B$. subtilis, while Kanamycin was the standard for $E$. coli and $S$. cerevisiae. Standards were spotted onto the plates as $1 \mu \mathrm{l}$ of solution $50 \mu \mathrm{g} / \mathrm{ml}$. Antimicrobial activity was indicated by clear zones of growth inhibition on the plates.

\subsection{Self-grooming behaviour}

Six and eight pre-emergence colonies of $P$. alternata and P. mellyi were collected in Malaysia and were housed at the Florence University in a closed box $(60 \times 60 \times 60 \mathrm{~cm})$ with ad libitum water, honey, prey and nest building material. Behavioural data were collected through direct observation of the wasps on their nests and indirectly by analysing brief (up to 300 frames/s) video sequences recorded with a digital photocamera (Casio Exilim EXF1Colonies). 


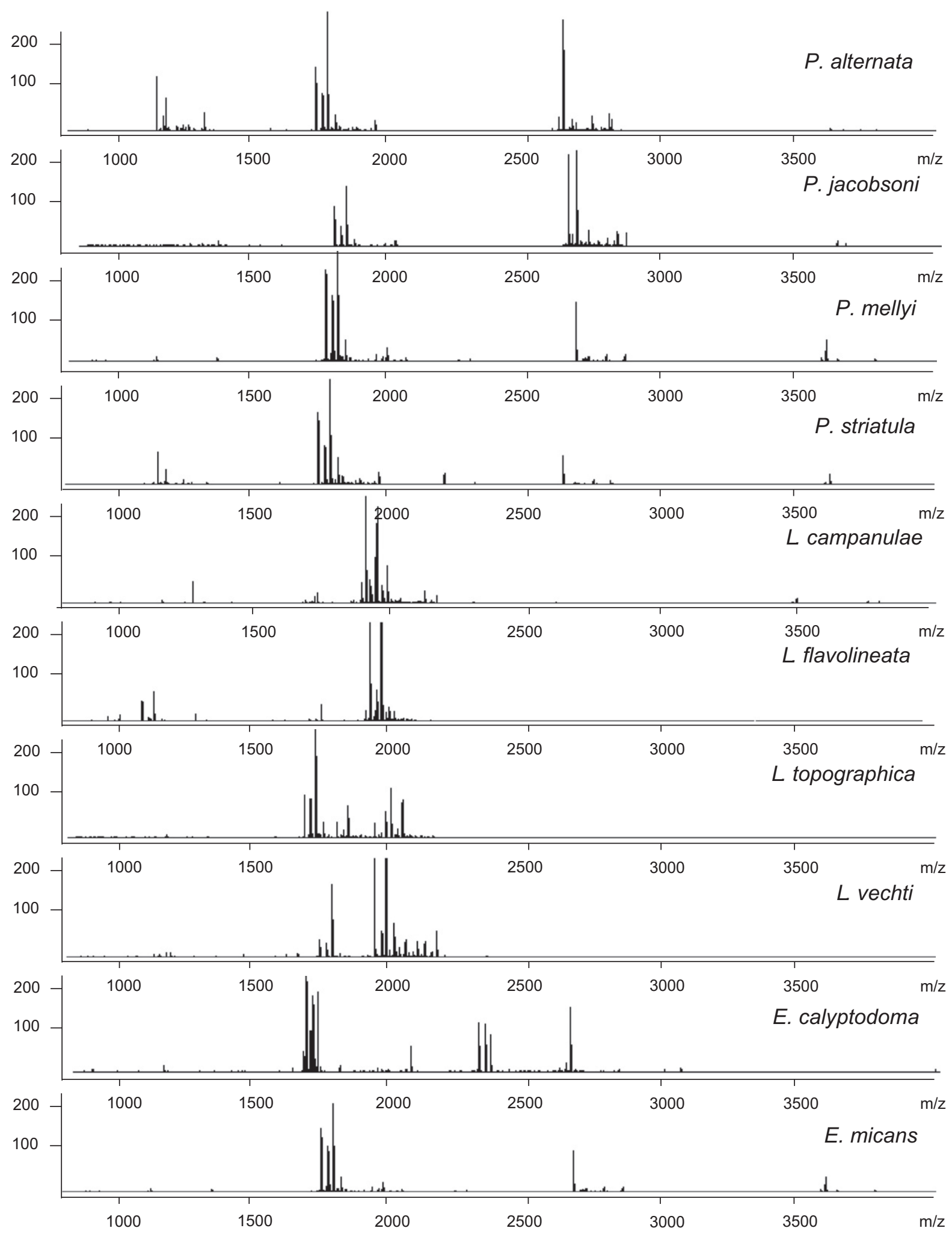

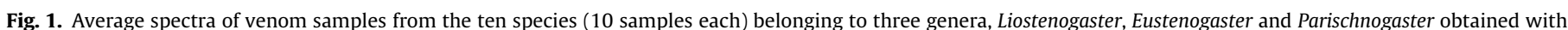
the CPT software.

\section{Results}

\subsection{Chemical results}

The nest material extraction ( $N=3$ for each species) lacks any compound in all the analysed samples. Thus, no venom peptides were found on the nests. On the contrary, all of the 100 venom spectra showed the presence of several compounds; eight spectra which could not be calibrated by CPT were excluded from the analysis. With a signal-to-noise threshold of 5.0 (on average spectrum) and a relative threshold base peak of 0.001 , the software found 49 main peaks (see Section 2.2.2), with molecular weight ranging 
from 1078 to $3323 \mathrm{Da}$ (as $z=1$, values of $m / z$ are reported in equivalent Daltons) (Fig. 1 and Table a, in Supplementary material).

\subsubsection{Comparison between venom and cuticular compounds}

In order to ascertain whether the venom and the cuticle compounds detected by the MALDI-TOF analysis were different, the cuticle and the venom spectra of each species were compared using the ClinProTools ${ }^{\mathrm{TM}}$. Table 1 reports the peaks (representing at least $1 \%$ of the total peak area in the spectrum) selected by the program for each species. CPT provided a number of peaks ranging from a minimum of 17 peaks in $L$. vechti to a maximum of 32 peaks in $P$. alternata. On average only the $1 \%$ of the peaks was exclusive of the insect cuticles while $17 \%$ were exclusively present in the venom. The remaining $81 \%$ of the peaks represents compounds found both in the venom and on the insect cuticle (see also Table 1). In this analysis, we considered a peak as not present in the venom or in the cuticle when it represented less than $1 \%$ of the total peaks area in the corresponding spectrum. On average, the peaks that are only present in the venom or in the cuticle represent only $1.9 \%$ (range 1.0-2.7) of the entire spectrum.

Also in the cluster analysis, all the venom and cuticular extracts belonging to the same species were grouped together except for $L$. campanulae and L. flavolineata (Fig. 2). Thus, the distances between the venom and the cuticle profiles of the same species seem to be smaller with respect to those between venom or cuticle profiles of different species.

\subsection{Antimicrobial results}

Both Penicillin G and Kanamycin, the antibiotics used as positive control, respectively, for B. subtilis and for E. coli and S. cerevisiae gave clear zones of growth inhibition on the plates (Table 2). Venoms belonging to Liostenogaster, Parischnogaster, Eustenogaster and Metischnogaster showed strong inhibitory activity against the growth of the Gram-positive B. subtilis, the Gram-negative E. coli and the yeast $S$. cerevisiae.

By contrast, no growth inhibition was found in any "nest material" microbiological test carried out on the Gram-positive B. subtilis, the Gram-negative E. coli and the yeast S. cerevisiae. For a more firm result the microbiological assays were repeated two times. The lack of antibiotic activity of nest extracts against bacteria and yeast was always confirmed for all the genera.

\subsection{Self-grooming}

In $P$. mellyi and $P$. alternata the sequence of self-grooming usually begins with the movements of the hind legs which rub each other and then the abdomen and the wings. Wings are rubbed against each other and against the gaster. Then, the hind legs are

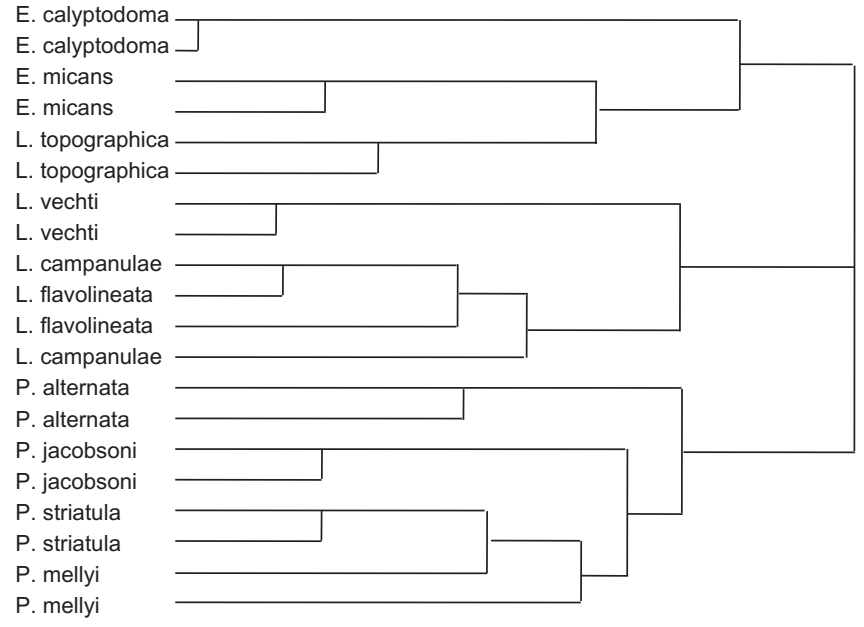

Fig. 2. Dendrogram resulting from cluster analysis performed by average linkage between groups (Pearson correlation). The relative distances among the groups were determined by the distances among their chemical profiles. (C, cuticular extract of a given species; $\mathrm{V}$, venom extract of a given species).

Table 2

Results of the agar diffusion tests, with extracts from four different genera. Mean values reported in the table indicate the diameters of zones of growth inhibition on the plates reported in millimetre.

\begin{tabular}{lccc}
\hline & E. coli & B. subtilis & S. cerevisiae \\
\hline Parischnogaster & 9.5 & 11 & 5 \\
Liostenogaster & 9 & 10.6 & 4.7 \\
Metischnogaster & 8.5 & 12 & 5 \\
Eustenogaster & 6.6 & 9.5 & 4.3 \\
Penicillin G/Kanamycin & 16 & 15.7 & 10.6 \\
\hline
\end{tabular}

rubbed against one of the middle legs and this is then passed to rub against the fore legs and the mouth parts. The fore legs then pass to rub the head, mouth parts and the antennae. The sequence is almost the same for males and females and basically similar in other genera (Sakagami and Yamane, 1990). Moreover the selfgrooming sequence is substantially the same to the behaviour with which some Parischnogaster species (P. nigricans serrei and P. jacobsoni) use to apply the Dufour's gland secretion to the nest as ant guard (Turillazzi and Pardi, 1981): a small ball of secretion is collected from the tip of the gaster by the hind legs and transported via one of the middle legs to the mouth parts to be applied on the nest substratum (Turillazzi and Pardi, 1981). This suggests that during self-grooming manoeuvre little drops of venom coming from the sting can be collected with legs by the wasps and applied all over the body.

Table 1

Number of principal peaks (representing at least $1 \%$ of the total peak area in the spectra) characteristic of the cuticle, of the venom and of both components selected by the ClinProTool when the venom and the cuticular spectra of each species were loaded together. Brackets report the number of peaks expressed in percentage.

\begin{tabular}{lllll}
\hline Species & $\begin{array}{l}\text { No. of peaks provided } \\
\text { by CPT }\end{array}$ & $\begin{array}{l}\text { No. of peaks present only } \\
\text { in the cuticle }\end{array}$ & $\begin{array}{l}\text { No. of peaks present only } \\
\text { in the venom }\end{array}$ & $\begin{array}{l}\text { No. of peaks present in both } \\
\text { venom and cuticle }\end{array}$ \\
\hline L. campanulae & 22 & $1(4)$ & $5(23)$ & $16(73)$ \\
L. flavolineata & 25 & 0 & $8(32)$ & $17(68)$ \\
L. topographica & 18 & 0 & $2(11)$ & $16(89)$ \\
L. vechti & 17 & $1(6)$ & $1(6)$ & $15(88)$ \\
E. calyptodoma & 18 & 0 & $2(11)$ & $16(89)$ \\
E. micans & 22 & 0 & $1(4)$ & $21(96)$ \\
P. alternata & 32 & $1(3)$ & $9(28)$ & $22(69)$ \\
P. mellyi & 27 & 0 & $4(15)$ & $23(85)$ \\
P. jacobsoni & 24 & 0 & $5(21)$ & $19(79)$ \\
P. striatula & 25 & 0 & $4(16)$ & $21(84)$ \\
\hline
\end{tabular}




\section{Discussion and conclusions}

Our findings demonstrate that the epicuticular medium molecular weight polar substances (roughly from 900 to $4000 \mathrm{Da}$ ) are identical to those found in the venom of all the analysed species, suggesting the venom reservoir as the primary source of cuticular polar substances. The direct comparison between venom and cuticular extracts in each species shows a quite perfect one to one correspondence of each single peak. Moreover, the cluster analysis is able to emphasise the coincidence of the profiles of the venom and of the cuticle for all the species, except for $L$. campanulae and $L$. flavolineata, probably due to the very similar composition of their chemical profiles (Baracchi et al., 2010). Even if Sumana and Starks (2004) showed that auto-grooming occurs largely for a cleaning function in Polistes dominulus, the most likely explanation for the presence of the venom on the cuticle remains that stenogastrine wasps use the cleaning movements also to smear this secretion on the body as suggested by our direct and indirect observations of $P$. alternata and $P$. mellyi self-grooming manoeuvre. The evidence that venom acts against bacteria and yeasts proves also that this secretion, present in conspicuous amounts on the cuticle, constitutes an antiseptic tool used by hover wasps as primary barrier to infections. This peculiar use of the venom, as already described for other arthropods, represents a clear investment in individual immunity (Torres-Larios et al., 2000; Orivel et al., 2001; Turillazzi et al., 2006; Lambardi et al., 2007; Baracchi and Turillazzi, 2010; Graystock and Hughes, 2011). Moreover, the investment of an hover wasp, insofar as social, in a individual immunity may raise a form of the so called "herd immunity" by reducing the risk of infection for neighbouring susceptible individuals (Frank, 1998). Since, resistance to parasitic infections has been one of the major factors that favoured the evolution of social insects (Otvos, 2000), it is likely that individuals gain immune benefits as a consequence of colony level selection rather than simply as a by-product of nestmate's personal immunity, being an instance of social immunity (sensu Cotter and Kilner, 2011). Also in M. drewseni, where the level of social behaviour is between the lowest in the subfamily, with colonies counting no more than one mother and one-two offspring (Turillazzi, 1990), the "herd immunity" can fall within the broader definition of social immunity given by Cotter and Kilner (2011). Differently from wasps' bodies, nest materials lack any venom peptides. Hoggard and co-workers (2011) found that species with paper nests showed significantly higher antimicrobial activity than those which excavates burrows and build mud nests. However, all the studied stenogastrine species, possess strong antimicrobial peptides independently from the material of their nests (mud or paper). This incongruence is probably due to the bias that all the species with mud or burrow nest used by Hoggard et al. (2011) are solitaries and all the species with paper nests are social. However, no mud as well as paper stenogastrine nest present antimicrobial peptides on its surface. In the hover wasps the nest does not seem to represent a "medium" where the venom is deposited in order to act as a social antiseptic tool as it was found in the eusocial paper wasp $P$. dominulus (Turillazzi et al., 2006). One possibility may be that the Stenogastrinae possess additional antiseptic devices to counteract the spread of pathogens on the nest with respect to Polistes wasps. In particular the most important difference is that while hover wasp adults eliminate the faecal pellets in the discharged peritrophic sacs emitted by the pupating larvae (Turillazzi and Pardi, 1981), Polistes larvae stock large quantities of faecal pellets in the bottom of the pupal cells. Further, Polistes wasps, even the tropical ones (Young, 1986), usually do not reuse the nests and build new combs probably to avoid problems linked to pathogens (Starr, 1978) while stenogastrine nests are commonly perpetual or reused. Regarding this habit it is interesting to observe that in Ropalidia marginata, a species belonging to the tribe Ropalidiini, which free their pupating larvae of their faeces extracting them from the bottom of the cells, several colony cycles may be repeated in the same nest (Gadagkar, 2001). Another explanation for the lack of the nest use as antiseptic medium by the hover wasps is simply that this form of collective immunity may required a sufficiently high number of individuals on the nest. Even in $L$. topographica, which is the species with the highest number of individuals among Stenogastrinae (up to 30 wasps, Baracchi et al., 2009) but still much less than the number of individuals of a colony of Polistes, the nest lacks antimicrobial peptides. In conclusion our findings suggest that a certain degree of sociality, or at least a sufficient number of individuals in a insect society, are thresholds to be reached for the rise of complex and efficient forms of collective immunity as mechanisms of resistance to disease.

\section{Appendix A. Supplementary data}

Supplementary data associated with this article can be found, in the online version, at doi:10.1016/j.jinsphys.2011.11.007.

\section{References}

Baracchi, D., Hashim, R., Teseo, S., Turillazzi, S., 2009. Basic social biology and nest architecture of Liostenogaster topographica Turillazzi 1999 (Hymenoptera: Stenogastrinae). Tropical Zoology 22, 15-25.

Baracchi, D., Turillazzi, S., 2010. Differences in venom and cuticular peptides in individuals of Apis mellifera (Hymenoptera: Apidae) determined by MALDI-TOF MS. Journal of Insect Physiology 56, 366-375.

Baracchi, D., Dapporto, L., Teseo, S., Hashim, R., Turillazzi, S., 2010. Medium molecular weight polar substances of the cuticle as tools in the study of the taxonomy, systematics and chemical ecology of tropical hover wasps (Hymenoptera: Stenogastrinae). Journal of Zoological Systematics and Evolutionary Research 48, 109-114.

Baracchi, D., Francese, S., Turillazzi, S., 2011. Beyond the antipredatory defence: honey bee venom function as a component of social immunity. Toxicon 58 , 550-557.

Billen, J., Morgan, E.D., 1998. Pheromone communication in social insects: source and secretion. In: Vander Meer, R.K., Breed, M.D., Winston, M.L., Espelie, K.E. (Eds.), Pheromone Communication in Social Insects. Westview Press, Oxford, pp. 3-33.

Brockmann, H.J., 1984. The evolution of social behaviour in insects. In: Krebs, J.R., Davies, N.B. (Eds.), Behavioural Ecology: An Evolutionary Approach. Blackwell, Oxford, pp. 340-361.

Chen, J., Henderson, G., Grimm, C.C., Lloyd, S.W., Laine, R.A., 1998. Termites fumigate their nests with naphthalene. Nature 392, 558-559.

Cotter, S.C., Kilner, R.M., 2011. Personal immunity versus social immunity. Behavioral Ecology 20, 1274-1281.

Cremer, S., Armitage, S.A.O., Schmid-Hempel, P., 2007. Social immunity. Current Biology 17, 693-702.

Frank, S.A., 1998. Inducible defence and the social evolution of herd immunity. Proceedings of the Royal Society of London B: Biological Sciences 265, 19111913.

Gadagkar, R., 2001. The Social Biology of Ropalida marginata. Towards an Understanding of the Evolution of Eusociality. Harvard University Press, 384 pp.

Graystock, P., Hughes, W.O.H., 2011. Disease resistance in a weaver ant, Polyrhachis dives, and the role of antibiotic-producing glands. Behavioral Ecology and Sociobiology. doi:10.1007/s00265-011-1242-y.

Hoggard, S.J., Wilson, P.D., Beattie, A.J., Stow, A.J., 2011. Social complexity and nest habits are factors in the evolution of antimicrobial defence in wasps. PLoS One 6, e21763.

Hölldobler, B., Wilson, E.O., 1990. The Ants. The Belknap Press of Harvard University Press, Cambridge, MA, 732 pp.

Hughes, D.P., Pierce, N.E., Boomsma, J.J., 2008. Social insect symbionts: evolution in homeostatic fortresses. Trends in Ecology and Evolution 23, 672-677.

Hughes, W.O., Boomsma, J.J., 2004. Genetic diversity and disease resistance in leafcutting ant societies. Evolution 58, 1251-1260.

Kuhn-Nentwig, L., 2003. Antimicrobial and cytolytic peptides of venomous arthropods. Cellular and Molecular Life Sciences 60, 2651-2668.

Lambardi, D., Tempestini, A., Cavallini, V., Turillazzi, S., 2007. Defence from entomopathogens in the paper waps Polistes dominulus (Christ, 1791): preliminary data. REDIA XC, 147-150.

Lawniczak, M.K.N., Barnes, A.I., Linklater, J.R., Boone, J.M., Wigby, S.W., Chapman, T., 2007. Mating and immunity in invertebrates. Trends in Ecology and Evolution $22,48-55$. 
ARTICLE IN PRESS

6

D. Baracchi et al./Journal of Insect Physiology $x x x$ (2011) $x x x-x x x$

Orivel, J., Redeker, V., Le Caer, J.P., Krier, F., Revol-Junelles, A.M., Longeon, A., Chaffotte, A., Dejean, A., Rossier, J., 2001. Ponericins, new antibacterial and insecticidal peptides from the venom of the ant Pachycondyla goeldii. The Journal of Biological Chemistry 276, 17823-17829.

Otvos, J.D., 2000. Antibacterial peptides from insects. Journal of Peptide Science 6, 497-511.

Obin, M.S., Vander Meer, R.K., 1985. Gaster flagging by fire ants (Solenopsis spp.): functional significance of venom dispersal behavior. Journal of Chemical Ecology 11, 1757-1768.

Park, N.G., Yamato, Y., Lee, S., Sugihara, G., 1995. Interaction of Mastoparan-B from venom of a hornet in Taiwan with phospholipid-bilayers and its antimicrobial activity. Biopolymers 36, 793-801.

Rosengaus, R.B., Lefebvre, M.L., Traniello, J.F.A., 2000. Inhibition of fungal spore germination by Nasutitermes: evidence for a possible antiseptic role of soldier defensive secretions. Journal of Chemical Ecology 26, 21-39.

Sadd, B.M., Schmid-Hempel, P., 2006. Insect immunity shows specificity in protection upon secondary pathogen exposure. Current Biology 16, 1206-1210.

Sakagami, S.F., Yamane, S., 1990. A behavior inventory of the females of two stenogastrine wasps Parischnogaster mellyi and Liostenogaster vechti (Hymenoptera, Vespidae). In: Sakagami, S.F., Ohgushi, R., Roubik, D.W. (Eds.), Natural History of Social Wasps and Bees in Equatorial Sumatra. Hokkaido University Press, Sapporo, pp. 73-96.

Schmid-Hempel, P., 1998. Parasites in Social Insects. Princeton University Press, Princeton, NJ, $392 \mathrm{pp}$.

Storey, G.K., Vander Meer, R.K., Boucias, D.G., McCoy, C.W., 1991. Effect of fire ant (Solenopsis invicta) venom alkaloids on the in vitro germination and development of selected entomogenous fungi. Journal of Invertebrate Pathology 58, 88-95.

Starr, C.K., 1978. Nest reutilization in North American Polistes (Hymenoptera: Vespidae): two possible selective factors. Journal of Kansas Entomology Society 51, 394-397.

Sumana, A., Starks, P.T., 2004. Grooming patterns in the primitively eusocial wasp Polistes dominulus. Ethology 110, 825-833.
Torres-Larios, A., Gurrola, G.B., Zamudio, F.Z., Possani, L.D., 2000. Hadrurin, a new antimicrobial peptide from the venom of the scorpion Hadrurus aztecus. European Journal of Biochemistry 267, 5023-5031.

Turillazzi, S., 1990. Notes on the biology, social behaviour and nest architecture of Metischnogaster drewseni (Saussure) (Hymenoptera, Stenogastrinae). Bollettino Zoologico 57, 331-339.

Turillazzi, S., 1991. The Stenogastrinae. In: Ross, K.G., Matthews, R.W. (Eds.), The Social Biology of Wasps. Cornell University Press, New York, pp. 74-98.

Turillazzi, S., 1996. Polistes in perspective: comparative social biology in Belonogaster and Stenogastrinae. In: Turillazzi, S., West-Eberhard, M.J. (Eds.), Natural History and Evolution of Paper-wasps. Oxford Science Publication, Oxford, UK, pp. 235-247.

Turillazzi, S., 2006. Polistes venom: a multifunctional secretion. Annales Zoologici Fennici 43, 488-499.

Turillazzi, S., Pardi, L., 1981. Ants guards on nests of Parischnogaster nigricans serrei (Du Buysson) (Stenogastrinae). Monitore zoologico Italiano 15, 1-7.

Turillazzi, S., Mastrobuoni, G., Dani, F.R., Moneti, G., Pieraccini, G., la Marca, G., Bartolucci, G., Perito, B., Lambardi, D., Cavallini, V., Dapporto, L., 2006. Dominulin A and B: two new antibacterial peptides identified on the cuticle and in the venom of the social paper wasp Polistes dominulus using MALDI-TOF, MALDI-TOF/TOF, and ESI-Ion Trap. Journal of the American Society for Mass Spectrometry 17, 376-383.

van Baalen, M., Beekman, M., 2006. The costs and benefits of genetic heterogeneity in resistance against parasites in social insects. The American Naturalist 167, 568-577.

Wilson-Rich, N., Spivak, M., Fefferman, N.H., Starks, P.T., 2009. Genetic, individual, and group facilitation of disease resistance in insect societies. Annual Review of Entomology 54, 405-423.

Young, A.M., 1986. Natural history notes on the social paper wasp Polistes erithrocephalus Latreille (Hymenoptera: Vespidae: Polistinae) in Costa Rica. Journal of the Kansas Entomological Sociey 59, 712-722.

Zasloff, M., 2002. Antimicrobial peptides of multicellular organisms. Nature 415, 389-395.

Please cite this article in press as: Baracchi, D., et al. From individual to collective immunity: The role of the venom as antimicrobial agent in the Steno-

gastrinae wasp societies. Journal of Insect Physiology (2011), doi:10.1016/j.jinsphys.2011.11.007 